\title{
Satisfaction with caregivers during labour among low risk women in the Netherlands: the association with planned place of birth and transfer of care during labour
}

Caroline C. Geerts ${ }^{1 *}$ D, Jeroen van Dillen ${ }^{2}$, Trudy Klomp ${ }^{1}$, Antoine L. M. Lagro-Janssen ${ }^{3}$ and Ank de Jonge ${ }^{1}$

\begin{abstract}
Background: The caregiver has an important influence on women's birth experiences. When transfer of care during labour is necessary, care is handed over from one caregiver to the other, and this might influence satisfaction with care. It is speculated that satisfaction with care is affected in particular for women who need to be transferred from home to hospital. We examined the level of satisfaction with the caregiver among women with planned home versus planned hospital birth in midwife-led care.
\end{abstract}

Methods: We used data from the prospective multicentre DELIVER (Data EersteLljns VERloskunde) cohort-study, conducted in 2009 and 2010 in the Netherlands. Women filled in a postpartum questionnaire which contained elements of the Consumer Quality index. This instrument measures 'general rate of satisfaction with the caregiver' (scale from 1 to 10, with cut-off of below 9) and 'quality of treatment by the caregiver' (containing 7 items on a 4 point Likert scale, with cut-off of mean of 4 or lower).

Results: Women who planned a home birth $(n=1372)$ significantly more often rated 'quality of treatment by caregiver' high than women who planned a hospital birth $(n=829)$. Primiparous women who planned a home birth significantly more often had a high rate (9 or 10) for 'general satisfaction with caregiver' (adj.OR 1.48; $95 \% \mathrm{Cl} 1.1,2.0)$. Also, primiparous women who planned a home birth and had care transferred during labour $(331 / 553 ; 60 \%)$ significantly more often had a high rate (9 or 10) for 'general satisfaction' compared to those who planned a hospital birth and who had care transferred $(1.44 ; 1.0-2.1)$. Furthermore, they significantly more often rated 'quality of treatment by caregiver' high, than 276/414 (67\%) primiparous women who planned a hospital birth and who had care transferred $(1.65 ; 1.2-2.3)$. No differences were observed for multiparous women who had planned home or hospital birth and who had care transferred.

Conclusions: Planning home birth is associated to a good experience of quality of care by the caregiver. Transferred planned home birth compared to a transferred planned hospital birth does not lead to a more negative experience of care received from the caregiver.

Keywords: Home childbirth, Transfer, Quality of care, Consumer Satisfaction, Caregiver, Midwifery

\footnotetext{
* Correspondence: c.geerts@vumc.nl

'Department of Midwifery Science, Academie Verloskunde Amsterdam

Groningen (AVAG) and the EMGO Institute for Health and Care Research, VU

University Medical Center Amsterdam, Van der Boechorststraat 7, 1081 BT

Amsterdam, The Netherlands

Full list of author information is available at the end of the article
} 


\section{Background}

Previously it was found that a substantial proportion of Dutch women look back negatively on their birth experience [1]. A negative description of caregivers and transfer of care from midwife-led primary to obstetrician-led secondary care during labour, were both associated with negative feelings about the birth experience three years postpartum. A negative birth experience is related to several negative (health) outcomes [2-6].

To monitor women's experiences, studies have obtained information on childbirth experience [7], and women's satisfaction with the care they received by care providers during labour [8]. Both outcomes are indicators of quality of care, and they are mutually related. Factors that are important to childbirth satisfaction, are based on the relationship with, and care provided by the caregiver [9]. In a thematic analysis of 62 studies, the relationship with the caregiver and support were identified as key attributes of the childbirth experience [9]. Therefore, the focus of the current study is on quality of care provided by caregivers which we will refer to as 'satisfaction with the caregiver'.

In case of transfer of care, multiple caregivers are involved in the labour process. It is important to gain insight in how the experience with the caregivers is affected when care is transferred. Especially, since referral rates in the Netherlands are rising and therefore an increasing number of women are affected by the consequences of transfer of care. During labour referral rates have risen for primiparous women from 50\% in 2008 to $63 \%$ in 2014 and from $17 \%$ to $26 \%$ for multiparous women $[10,11]$. Caregivers have the potential to make an important difference to women's experience when transfer of care is necessary [12].

In the Netherlands, low-risk women receive midwifeled care from primary care midwives. These are women with a singleton pregnancy of a fetus in cephalic presentation who do not have any medical or obstetric risk factors that are an indication for obstetrician-led care, and who start labour between 37 and 42 weeks. If complications or obstetric risk factors occur during pregnancy, labour, or after birth, women have care transferred from midwife-led to obstetrician-led care. In obstetrician-led care women may receive care from clinical midwives, obstetric registrars, and obstetric nurses, under the final responsibility of an obstetrician or by obstetricians themselves. After transfer, the primary care midwife may provide support to women, but this does not happen in all cases. The indications for transfer of care are layed out in the obstetric indication list (VIL) [13]. Women who still receive midwife-led care at term can choose to give birth at home or in hospital, assisted by their primary care midwife.
Recently it was suggested that transfer of care during labour affects patient satisfaction particularly among women who plan home birth [14]. It is speculated that transportation from home to hospital during labour might contribute to this. Additionally expectations (giving birth at home) are not met.

The primary aim of this study was to evaluate satisfaction with the caregiver among women who planned a home or a hospital birth in midwife-led care. Secondly, we studied the effect of transfer of care in a planned home birth compared to transfer of care in a planned hospital birth on satisfaction with the caregiver.

\section{Methods \\ DELIVER-study}

The Deliver study is a multicenter prospective cohort study into the quality, organisation and accessibility of midwifery care in the Netherlands, which was described extensively elsewhere [15].

Briefly, the means of recruitment of clients was through midwifery practices. Purposive sampling was used to select practices, using three stratification criteria: region (north, centre, south), level of urbanisation (urban or rural area), and practice type (dual or group practice). Twenty of the 519 midwifery practices across the Netherlands participated in this study. Between September 2009 and December 2010 client data were collected using questionnaires. Clients who received antenatal care and who gave informed consent, were given up to three questionnaires: one before 34 weeks gestation (the 1st questionnaire), one between 34 weeks gestation and birth (the 2nd questionnaire), one approximately 6 weeks postpartum (the 3rd questionnaire). The response rate of the DELIVER study was $62 \%$.

The Deliver client data were linked to primary midwife-led care data from the Netherlands Perinatal Register (PRN, "Landelijke Verloskundige Registratie", LVR1). Linkage was successful in $76.1 \%$ of the women included in this study.

For the women with successful linkage, agreement between LVR1 and Deliver data for women who started labour in midwife-led care was $99.1 \%$ for vacuum or forceps extraction, 99.9\% for caesarean section and 99.4 (hospital) to $94.7 \%$ (home) for actual place of birth. In case of disagreement, we used data from the DELIVER study.

\section{Study population}

For this study, participants with singleton term pregnancies that were in midwifery care at the onset of labour were selected. The definition for onset of labour in primary care is based on information from the LVR1 database. This information showed internal inconsistencies in $3.7 \%$ of the cases. Women who had care transferred 
for prolonged rupture of membranes ( $>24 \mathrm{~h}$ without contractions) were excluded. Among these women, transfer to secondary care occurred before start of the dilation (first) stage, and thus planned place of birth is unlikely to have affected satisfaction with the caregiver. Women who were transferred to secondary care during pregnancy and women who were advised to give birth in hospital in midwife led care because of a condition that would increase the risk of complications for the woman or baby were also excluded.

\section{Planned place of birth and transfer of care during labour} Planned place of birth (home or hospital under midwifeled care) is recorded on the LVR-1 form at some point during pregnancy. This information is missing for some women; midwives may forget to record the details or the women may not have made a decision on where to give birth until the onset of labour. The number of women with unknown planned place of birth in this study will be reported in the Results section.

When complications arise such as listed in the VIL [13], care is transferred from midwife-led to obstetrician-led care. When a woman is at home, this requires transport to a hospital facility prior to transfer of care, either by car, or if transport by car is too inconvenient or in case of an emergency, by ambulance. In this study, both transfer during labour or immediately postpartum, were defined as transfer of care.

From information on planned and actual place of birth two groups were formed of women who were transferred, according to their planned place of birth. Three groups were formed for women who gave birth in primary care (and thus were not transferred), see Table 1 :

In the analyses for the primary research question planned hospital birth (including hosp-transferred and hosp-hosp) was the comparison group, because the hypothesis was that quality of treatment and general satisfaction with the caregiver is negatively influenced by transportation from home to hospital when transfer of care is necessary.

\section{Satisfaction with caregiver}

Satisfaction with the caregiver during labour was assessed with the 3rd postpartum DELIVER client questionnaire, which was filled in 6 weeks postpartum on average (see Additional file 1).

Satisfaction of care by caregiver was assessed using 1 : general and 2: evaluative questions which both were adapted from the Consumer Quality Index (CQ-index) for maternity care. This instrument was developed to measure client experiences. The questions were identified and validated in item- and factor analyses $[8,16]$. The cut-off values for both outcomes were chosen based on the fact that self-reported satisfaction with care is usually very high [17], particularly in relation to maternity care [18]. We aimed to identify whether a planned home or hospital birth is associated to rates that indicate anything less than very good care.

1. 'General ratings of satisfaction' with care provided by caregiver during labour ranged from $1=$ worst possible care, to $10=$ best possible care. The rate was dichotomised into 'below 9', and 'equal to and above 9' to distinguish between very high and (somewhat) lower level of satisfaction with care.

2. The evaluative questions, measuring 'quality of treatment by a particular caregiver' during labour, consisted of 7 items: feeling in safe hands, having things explained in an understandable way, being treated with respect, being listened to carefully, being taken seriously, being given enough time, being given enough opportunity to ask questions. Questions were framed as: "Did you experience....?" with answers ranging from $1=$ never, to $4=$ always. The mean of the total score of the 7 items was calculated, ranging from 1 to 4 [8]. We used a cut-off of 'below 4' and

Table 1 Definition of planned place of birth and transfer

\begin{tabular}{ll} 
Planned home birth: & Birth planned at home in midwife-led care. \\
Planned hospital birth: & Birth planned in hospital under midwife-led care. \\
Transfer: & $\begin{array}{l}\text { Women who had care transferred from midwife-led to obstetrician-led during labour or } \\
\text { immediately postpartum. }\end{array}$ \\
Home - transfer: & $\begin{array}{l}\text { planned home birth but transfer to obstetrician-led care during labour or immediately } \\
\text { postpartum. }\end{array}$ \\
Hosp - transfer: & $\begin{array}{l}\text { planned hospital birth but transferred to secondary care during labour or immediately } \\
\text { postpartum. }\end{array}$ \\
No transfer: & Women who gave birth in midwife-led care without being transferred. \\
Home - home: & birth planned at home and actual birth at home under midwife-led care \\
Hosp- hosp: & planned hospital, actual hospital birth in midwife-led care \\
\hline
\end{tabular}


'equal to 4'. The internal consistency of the 7 items was high, with a Cronbach's alpha of 0.93 .

The cut-off of 9 was chosen, based on a previous study showing that 'general satisfaction with caregiver' during labour and birth was rated 9 or 10 in more than half of the women. The cut-off for 'quality of treatment' was set on 4 vs lower than $4(1,2,3)$, based on the high mean score of this variable in the previous study (e.g. 3.61 to 3.92) [8].

\section{Confounding factors}

Maternal age, ethnic background (Dutch, western background or non-western background) and social status (score 1-4) were taken into account, because of their association with planned place of birth $[19,20]$ and satisfaction with childbirth [21]. For social status we used the score developed by the Netherlands Institute for Social Research (SCP), using postal codes, based on education, income and employment rates. A low score equals high social status (www.scp.nl/Onderzoek/Lopend_onderzoek/A_Z_alle_lopende_onderzoeken/Statusscores).

Results were presented separately by parity, because the association between planned place of birth and satisfaction with the caregiver might differ for primi- and multiparous women. Once a woman has given birth, her choice about place of birth is influenced by her previous experience [22], and multiparous women are more satisfied with the birth experience and thus might rate satisfaction with care differently [21].

\section{Potential explanatory factors}

Some factors were assessed to explore if they could explain associations between planned place of birth and satisfaction with the caregiver. Some of these factors are only applicable to women in obstetrician-led care. However, both among the women who planned home birth as well as among the women who planned hospital birth in midwife-led care, transfer during labour to obstetricianled care occurred in some cases, and consequently some women who planned home or hospital birth in midwifeled care received medical pain relief during labour for example.

Medical pain relief (yes-no) and experience of labour pain (rating scale from 1 to 10) were taken into account, because they have been reported to influence satisfaction with childbirth and consequently might influence satisfaction with the caregiver [21]. Management and experience of labour pain is different for women planning hospital birth, compared to women planning a home birth. The role of medical interventions, including augmentation, vaginal instrumental delivery and caesarean section was investigated [21]. Finally, in an explanatory analysis the extent to which transfer of care (yes/no) could explain possible differences in the association between planned place of birth and satisfaction with the caregiver was assessed.

\section{Data-analysis}

Baseline and pregnancy related characteristics and labour outcomes were compared between low risk women who planned to give birth at home versus women who planned to give birth in hospital using student's t-test for continuous and chi-square test for categorical characteristics. Mean scores of 'general satisfaction with the caregiver' and 'quality of treatment' were calculated for planned home and hospital birth, to calculate the minimal important difference $(\mathrm{MID}=0.2$ * $\left.\mathrm{SD}_{\text {hospital }}\right)[23,24]$. It is a score that reflect differences in a client derived outcome of an intervention, that is meaningful to the client. The association between planned place of birth (home/ hospital) and satisfaction with the caregiver during labour (defined as 1: 'general rating of satisfaction with the caregiver' and, 2: the 'quality of treatment by the caregiver') was analysed using multilevel logistic regression analysis with two levels; the midwifery practice level and individual level, in order to account for clustering of women within midwifery practices. In similar models the association between planned place of birth and the 7 separate evaluative questions for 'quality of treatment by the caregiver' were analysed, as well as the association between planned place of birth and transfer (home-transfer, hosp-transfer) or not (home-home, hosp-home, hosp-hosp) with 'general satisfaction with the caregiver' and 'quality of treatment'. To examine the effect of transfer in a planned home birth on satisfaction with the caregiver, as well as the overall effect of satisfaction in a planned home birth compared to a planned hospital birth, planned hospital was used as the reference.

Odds ratios and 95\% confidence intervals were presented. Dummy variables were constructed in case of $>2$ categories. Adjustments were made for confounders using multivariable models. Additionally, potential explanatory factors were added separately in the models. Finally, a sensitivity analysis was performed including women with and without discrepancies in the definition for start of labour in primary care.

All analyses were stratified for parity. The analysis were performed using SPSS 20.0 and Stata 10. Statistical significance was considered with a $p$-value $<0.05$.

\section{Results}

In the DELIVER dataset, 6021 women had data linked to LVR1. In Fig. 1 is it shown that data from the postpartum questionnaire (PPQ) were available for 3783 of these women. Of these, 1394 women were excluded because of a medium risk indication, prolonged rupture of 


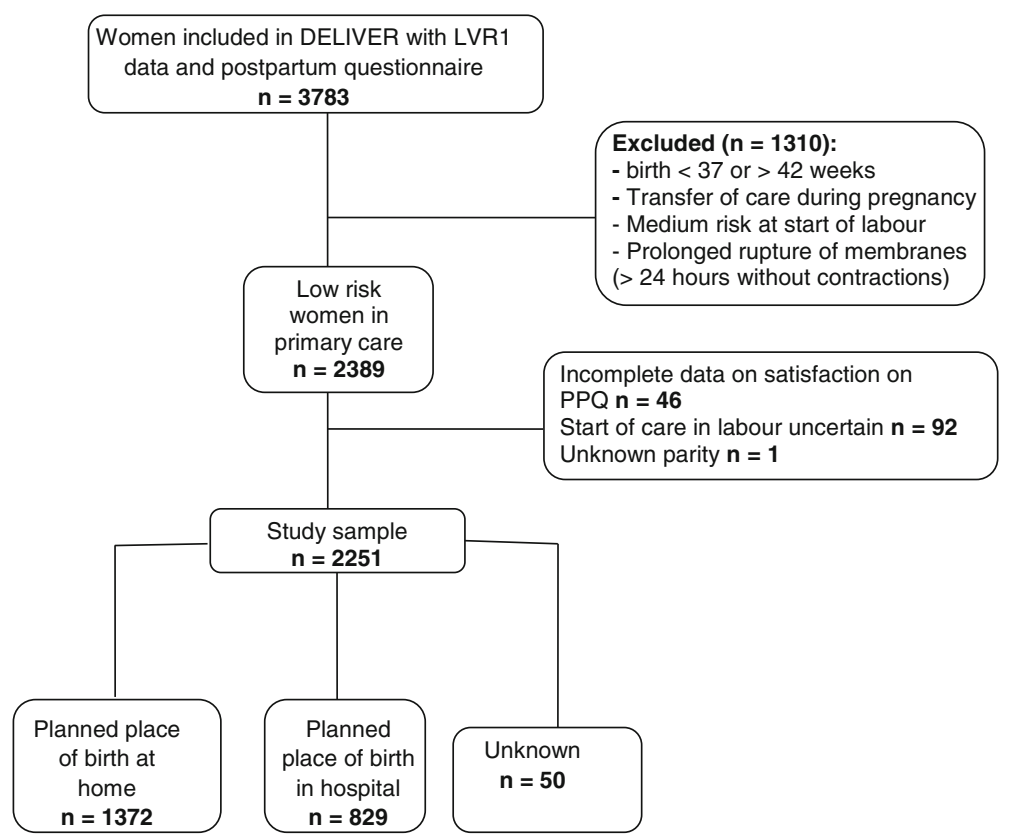

Fig. 1 Selection of low risk women who started labour in primary care in the Deliver study

membranes without contractions, preterm or postterm birth or transfer of care during pregnancy. Of the remaining 2389 women, 92 were excluded because of discrepancies in the definition for onset of labour in midwife-led care, 46 had incomplete data about satisfaction with the caregiver on the PPQ and 1 had unknown parity. Of the remaining 2251 eligible women, 1372 women planned a home birth (61\%) and 829 (37\%) women planned a hospital birth. Planned place of birth was unknown in 50 women (2\%).

Furthermore, 826 women had care transferred during labour either intrapartum $(n=726)$ or immediately postpartum $(n=99)$.

Table 2 shows that women who chose to give birth at home were significantly less likely to be primiparous, of ethnic minority background and below 25 years or above 35 years, compared to women who chose hospital birth. Women planning a home birth significantly less often had augmentation or were transferred to secondary care and they had a significant lower rate of instrumental vaginal delivery, caesarean section, pharmacological pain relief and experience of labour pain. Both the mean score for 'general satisfaction with the caregiver' and 'quality of treatment' were significantly higher for women who planned home birth. The MID for 'general rate of satisfaction' was $0.26(0.2 * 1.3)$ and for 'quality of treatment' $0.08\left(0.2^{*} 0.4\right)$.

Planned place of birth and satisfaction with the caregiver Table 3 shows that for primiparous women during labour both the 1: 'general rate of satisfaction' with the caregiver, and 2: 'quality of treatment', were significantly more often high among women planning a home birth compared to women planning a hospital birth, taking into account confounders and clustering of women within midwifery practices. For multiparous women, 2: 'quality of treatment' was statistically significantly more often high (equal to 4) among women who planned a home birth.

The separate items of the measure for 2: 'quality of treatment by the caregiver' in Table 4 shows that primiand multiparous women who planned a home birth significantly more often had the feeling that they were 'in safe hands with the caregiver' and that the caregiver 'took them seriously', compared to women who planned a hospital birth. In addition, nulliparous women who planned a home birth significantly more often stated that 'the caregiver explained things in an understandable way'. Multiparous women who planned a home birth significantly more often experienced that 'the caregiver listened to them carefully'.

\section{Explanatory analysis}

For primiparous women, the significantly lower 'general rating of satisfaction with the caregiver' during labour for women who planned hospital birth, was no longer present after adjustment for medical pain relief (data not shown in table): adjusted OR 1.31 (95\% CI 0.95-1.80). Since women who planned hospital birth more often received medical pain relief, the results of the explanatory analyses suggest that satisfaction with the caregiver was lower for women who received medical pain relief and 
Table 2 Baseline and pregnancy related characteristics and labour outcomes for planned place of birth of women in the primary care setting at the start of labour

\begin{tabular}{|c|c|c|c|}
\hline & $\begin{array}{l}\text { Planned } \\
\text { home birth }\end{array}$ & $\begin{array}{l}\text { Planned } \\
\text { hospital birth }\end{array}$ & $p$-value \\
\hline & $n=1329$ & $n=829$ & \\
\hline \multicolumn{4}{|l|}{ Baseline characteristics } \\
\hline Parity, n (\%) & & & $<0.001$ \\
\hline Primiparous & $577(42.1)$ & $414(49.9)$ & \\
\hline Multiparous & $795(57.9)$ & $415(50.1)$ & \\
\hline Gestational age, n (\%) & & & 0.19 \\
\hline 37 weeks & $38(2.8)$ & $33(4.0)$ & \\
\hline $38-40$ weeks & $1064(77.6)$ & $648(77.6)$ & \\
\hline 41 weeks & $270(19.7)$ & $148(17.9)$ & \\
\hline Maternal age, $n(\%)$ & & & 0.02 \\
\hline$<25$ years & $105(7.7)$ & $74(9.3)$ & \\
\hline $25-35$ years & $1040(75.8)$ & $583(70.3)$ & \\
\hline$>35$ years & $227(16.5)$ & $172(20.7)$ & \\
\hline Ethnic background, $n(\%)$ & & & $<0.001$ \\
\hline Dutch & $1244(90.9)$ & $645(78.1)$ & \\
\hline Western background & $74(5.4)$ & $87(10.5)$ & \\
\hline Non-western background & $51(3.7)$ & $94(11.4)$ & \\
\hline Socioeconomic position, n (\%) & & & 0.57 \\
\hline 1st tertile & $353(25.8)$ & $228(27.7)$ & \\
\hline 2nd tertile & $645(47.2)$ & $386(46.8)$ & \\
\hline 3rd tertile & $369(27.0)$ & $210(25.5)$ & \\
\hline \multicolumn{4}{|l|}{ Maternal outcomes and interventions } \\
\hline \multicolumn{4}{|l|}{ Experience of labour pain, mean (sd) } \\
\hline first stage & $7.2(2.0)$ & $7.7(1.9)$ & $<0.001$ \\
\hline second stage & $6.9(2.2)$ & $7.2(2.2)$ & 0.001 \\
\hline $\begin{array}{l}\text { General rating of care by caregiver, } \\
\text { mean (sd) }\end{array}$ & $9.1(1.1)$ & $8.9(1.3)$ & 0.001 \\
\hline Quality of treatment, mean (sd) & $3.9(0.3)$ & $3.8(0.4)$ & $<0.001$ \\
\hline Transfer during labour, n (\% referred) & $435(31.7)$ & $390(47.0)$ & $<0.001$ \\
\hline Medical pain relief ${ }^{a}, n$ (\% yes) & $141(10.3)$ & $184(22.4)$ & $<0.001$ \\
\hline $\begin{array}{l}\text { Instrumental/ operative delivery, } \\
\mathrm{n}(\%)\end{array}$ & & & 0.02 \\
\hline Vacuum-/ forceps extraction & $123(9.0)$ & $99(12.0)$ & \\
\hline Secondary caesarean section & $48(3.5)$ & $39(4.7)$ & \\
\hline Augmentation, $\mathrm{n}$ (\% yes) & $205(14.9)$ & $171(20.7)$ & 0.001 \\
\hline \multicolumn{4}{|l|}{ Neonatal outcomes } \\
\hline Apgar score < 7, n (\%) & $8(0.6)$ & $7(0.8)$ & 0.47 \\
\hline $\begin{array}{l}\text { Complications directly postpartum, } \\
\text { n (\%) }\end{array}$ & $21(1.6)$ & $14(1.8)$ & 0.72 \\
\hline
\end{tabular}

Missings: maternal age $n=1$; ethnic background $n=10$; socioeconomic position $n=10$; general rating of care by caregiver $n=28$; CQ index score $n=2$ ${ }^{a}$ Medicinal pain relief includes epidural (193), remiphentanyl (87) and opioids (86)

that this partly explains why women who planned hospital birth in midwife-led care rated satisfaction with caregiver lower. Another explanation was provided by transfer of care: the association was abolished when adjusting for transfer of care during labour: adjusted OR 1.33 (0.96-1.83). Adjustment for medical interventions (e.g. vaginal instrumental delivery, caesarean section and augmentation) or experience of labour pain did not have an effect on the associations.

\section{Transfer and satisfaction with caregiver}

Compared to women who planned a hospital birth and who were transferred during labour as the reference group (hosp-transfer), 'general rating of satisfaction with care' and 'quality of treatment by the caregiver' during labour was significantly more often high for primiparous women who planned a home birth and who were transferred (home-transfer; Table 5). No differences were observed in any measure of satisfaction with care for multiparous women who planned a home or hospital birth and who were transferred (Table 5; transfer).

Table 5, no transfer, shows that multiparous women who planned a hospital birth but who actually gave birth at home (hosp-home) significantly more often gave a higher rate for 'general satisfaction with the caregiver' than multiparous women who planned a hospital birth and who actually gave birth in hospital in midwife-led care (hosp-hosp). Multiparous women who planned and had a birth at home (home-home) significantly more often rated 'quality of treatment of care' high compared to women who planned a hospital birth and who actually gave birth in hospital in midwife-led care (hosp-hosp).

The group who planned a home birth but actually gave birth in hospital in midwife-led care was too small for analysis.

\section{Sensitivity analysis}

Sensitivity analysis of 2286 low-risk women (the eligible study population including 85 women with discrepancies in the definition of start of labour in midwife-led care and known planned place of birth) for the association of planned place of birth and 1: 'general rating of satisfaction with the caregiver' and 2: 'quality of treatment of care', showed similar results.

\section{Discussion}

Main findings

Primiparous women in midwife-led care at the start of labour who planned a home birth were significantly more satisfied with the care they received from the caregiver during labour than women who planned a hospital birth. They rated 'quality of treatment provided by the caregiver' significantly higher when they had care transferred compared to primiparous women who planned a hospital birth and who had care transferred. Multiparous 
Table 3 Planned place of birth and 1: general rate of satisfaction with the caregiver $(<9 / \geq 9)$ and 2: quality of treatment by caregiver during labour and birth (below 4/equal to 4), by parity

\begin{tabular}{|c|c|c|c|c|c|c|c|c|}
\hline \multirow[b]{3}{*}{$\begin{array}{l}\text { 1: General rating of satisfaction } \\
\text { with caregiver }\end{array}$} & \multicolumn{4}{|c|}{ Primiparous women } & \multicolumn{4}{|c|}{ Multiparous women } \\
\hline & \multicolumn{4}{|c|}{ Multilevel } & \multicolumn{4}{|c|}{ Multilevel } \\
\hline & Total N & $N(\%) \geq 9$ & OR $(95 \% \mathrm{Cl})$ & Adjusted $^{\mathrm{a}}$ OR $(95 \% \mathrm{Cl})$ & Total N & $N(\%) \geq 9$ & OR $(95 \% \mathrm{Cl})$ & $\begin{array}{l}\text { Adjusted } \text { a }^{\mathrm{a}} \text { OR } \\
(95 \% \mathrm{Cl})\end{array}$ \\
\hline Planned home & 575 & $408(71.0)$ & $1.50(1.1,2.0)^{* *}$ & $1.48(1.1,2.0)^{* *}$ & 788 & $625(79.3)$ & $1.07(0.8,1.4)$ & $1.08(0.8,1.5)$ \\
\hline Planned hospital & 404 & $249(61.6)$ & 1 & 1 & 406 & $317(78.1)$ & 1 & 1 \\
\hline $\begin{array}{l}\text { 2: Quality of treatment by } \\
\text { caregiver }\end{array}$ & & $N(\%)=4$ & & & & $N(\%)=4$ & & \\
\hline Planned home & 576 & $428(74.3)$ & $1.74(1.3,2.3)^{* *}$ & $1.79(1.3,2.4)^{* *}$ & 795 & $631(79.4)$ & $1.65(1.3,2.2)^{* *}$ & $1.58(1.2,2.1)^{* *}$ \\
\hline Planned hospital & 413 & $260(63.0)$ & 1 & 1 & 413 & $289(70.0)$ & 1 & 1 \\
\hline
\end{tabular}

** $p<0.05$

a adjusted for maternal age, ethnic background (Dutch, western background, non-western background) and socioeconomic status (quartiles)

women who planned a home birth were significantly more satisfied with 'quality of treatment' and when they had care transferred they were equally satisfied with the care provided by the caregiver compared to multiparous women who planned a hospital birth and who had care transferred during labour.

\section{Strengths and limitations}

For this study, we used data from a prospective cohort study. Although a randomised controlled trial would be preferred for planned place of birth this was shown not to be feasible [25]. Therefore, due to the observational nature of this study, we adjusted the association for confounders.

Table 4 Satisfaction with caregiver concerning different items of quality of treatment (below 4/equal to 4) in relation with planned place of birth of women under midwife led care at the start of labour

\begin{tabular}{|c|c|c|c|c|c|}
\hline \multicolumn{3}{|l|}{ Primiparous women } & \multicolumn{3}{|l|}{ Multiparous women } \\
\hline & Crude & Adjusted $^{\mathrm{a}}$ & & Crude & Adjusted $^{\mathrm{a}}$ \\
\hline No (\%) always $(=4)$ & OR $(95 \% \mathrm{Cl})$ & OR $(95 \% \mathrm{Cl})$ & No (\%) always $(=4)$ & OR $(95 \% \mathrm{Cl})$ & OR $(95 \% \mathrm{Cl})$ \\
\hline
\end{tabular}

Did you feel in safe hands with the caregiver?

$\begin{array}{lllllll}\text { planned home } & 577 & 497(86.1) & 1.74(1.2,2.5)^{* *} & 1.57(1.1,2.3)^{* *} & 795 & 700(88.1) \\ \text { planned hospital } & 414 & 323(78.0) & 1 & 1 & 413 & 341(82.6)\end{array}$

Did the caregiver explain things in an understandable way?

$\begin{array}{lll}\text { planned home } & 576 & 514(89.2) \\ \text { planned hospital } & 414 & 336(81.2)\end{array}$

Did the caregiver treat you with respect?

$\begin{array}{lll}\text { planned home } & 577 & 544(94.3) \\ \text { planned hospital } & 414 & 382(92.3)\end{array}$

Did the caregiver listen to you carefully?

$\begin{array}{lll}\text { planned home } & 576 & 510(88.5) \\ \text { planned hospital } & 414 & 350(84.5)\end{array}$

Did the caregiver take you seriously?

$$
\begin{array}{lll}
\text { planned home } & 576 & 519(90.1) \\
\text { planned hospital } & 414 & 354(85.5)
\end{array}
$$

$\begin{array}{llll}1.91(1.3,2.8)^{* *} & 1.93(1.3,2.9)^{* *} & 795 & 718(90.3) \\ 1 & 1 & 413 & 358(86.7) \\ & & & \\ 1.36(0.8,2.4) & 1.27(0.7,2.3) & 795 & 751(94.5) \\ 1 & 1 & 413 & 380(92.0) \\ 1.42(0.97,2.1) & 1.46(0.99,2.1) & 795 & 720(90.6) \\ 1 & 1 & 413 & 351(85.0) \\ 1.57(1.1,2.3)^{* *} & 1.54(1.0,2.3)^{* *} & 795 & 741(93.2) \\ 1 & 1 & 413 & 361(87.4)\end{array}$

Did the caregiver spent sufficient time with you?

$\begin{array}{lllllll}\text { planned home } & 576 & 488(84.7) & 1,49(1.1,2.1)^{* *} & 1,41(0.99,2.0) & 795 & 700(88.1) \\ \text { planned hospital } & 413 & 325(78.7) & 1 & 1 & 413 & 347(84.0)\end{array}$

Did the caregiver give you enough opportunity to ask questions?

\begin{tabular}{llllllll} 
planned home & 576 & $527(91.5)$ & $1,51(0.99,2.3)$ & $1,41(0.9,2.2)$ & 795 & $746(93.8)$ & $1.48(0.9,2.3)$ \\
planned hospital & 414 & $363(87.7)$ & 1 & 1 & 413 & $375(90.8)$ & 1 \\
\hline
\end{tabular}

**p $<0.05$

a adjusted for maternal age, ethnic background (Dutch, western background, non-western background) and socioeconomic status (quartiles)

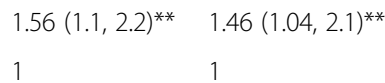


Table 5 Odds ratios for the association between 1: general rate of satisfaction with the caregiver $(<9 / \geq 9)$ and 2: quality of treatment by caregiver during labour and birth (below 4/ equal to 4) among women who were transferred (transfer) during labour and among those who were not transferred (no transfer)

\begin{tabular}{|c|c|c|c|c|c|c|c|c|}
\hline \multicolumn{5}{|l|}{ Primiparous women } & \multicolumn{4}{|c|}{ Multiparous women } \\
\hline \multirow[b]{2}{*}{$\begin{array}{l}\text { 1: General rating of satisfaction } \\
\text { with caregiver }\end{array}$} & \multirow[b]{2}{*}{ Total N } & \multirow[b]{2}{*}{$N(\%) \geq 9$} & \multicolumn{2}{|l|}{ Multilevel } & \multicolumn{4}{|c|}{ Multilevel } \\
\hline & & & OR $(95 \% \mathrm{Cl})$ & $\begin{array}{l}\text { Adjusted }{ }^{a} \text { OR } \\
(95 \% \mathrm{Cl})\end{array}$ & Total N & $N(\%) \geq 9$ & OR $(95 \% \mathrm{Cl})$ & $\begin{array}{l}\text { Adjusted }{ }^{a} \text { OR } \\
(95 \% \mathrm{Cl})\end{array}$ \\
\hline \multicolumn{9}{|l|}{ Transfer } \\
\hline planned home-transfer & 329 & $208(63.2)$ & $1.53(1.1,2.2)^{* *}$ & $1.44(1.0,2.1)^{* *}$ & 104 & $70(67.3)$ & $0.97(0.5,1.7)$ & $1.11(0.6,2.1)$ \\
\hline planned hosp-transfer & 267 & $139(52.1)$ & 1 & 1 & 109 & $74(67.9)$ & 1 & 1 \\
\hline \multicolumn{9}{|l|}{ No transfer } \\
\hline planned home-home & 222 & $181(81.5)$ & $1.41(0.7,2.7)$ & $1.48(0.8,2.9)$ & 652 & $529(81.1)$ & $1.21(0.8,1.8)$ & $1.21(0.8,1.8)$ \\
\hline planned hosp-home & 39 & $34(87.2)$ & $2.14(0.7,6.4)$ & $2.04(0.7,6.2)$ & 100 & $89(89.0)$ & $2.28(1.1,4.7)^{* *}$ & $2.31(1.1,4.7)^{* *}$ \\
\hline planned hosp-hosp & 98 & $76(77.6)$ & 1 & 1 & 197 & $154(78.2)$ & 1 & 1 \\
\hline $\begin{array}{l}\text { 2: Quality of treatment by } \\
\text { caregiver }\end{array}$ & & $N(\%)=4$ & & & & $N(\%)=4$ & & \\
\hline \multicolumn{9}{|l|}{ Transfer } \\
\hline Planned home & 330 & $225(68.2)$ & $1.61(1.2,2.2)^{* *}$ & $1.65(1.2,2.3)^{* *}$ & 104 & $78(75.0)$ & $1.72(0.9,3.1)$ & $1.76(0.9,3.3)$ \\
\hline Planned hospital & 275 & $157(57.1)$ & 1 & 1 & 113 & $72(63.7)$ & 1 & 1 \\
\hline \multicolumn{9}{|l|}{ No transfer } \\
\hline planned home-home & 222 & $185(83.3)$ & $1.73(0.9,3.2)$ & $1.81(0.9,3.4)$ & 659 & $530(80.4)$ & $1.87(1.3,2.7)^{* *}$ & $1.80(1.3,2,6)^{* *}$ \\
\hline planned hosp-home & 39 & $29(74.3)$ & $1.01(0.4,2.4)$ & $0.94(0.4,2.3)$ & 101 & $80(79.2)$ & $1.74(0.9,3.1)$ & $1.70(0.9,3.0)$ \\
\hline planned hosp-hosp & 99 & $74(74.7)$ & 1 & 1 & 199 & $137(68.8)$ & 1 & 1 \\
\hline
\end{tabular}

${ }^{* *} p<0.05$

adjusted for maternal age, ethnic background (Dutch, western background, non-western background) and socioeconomic status (quartiles)

In addition, clustering of women within midwifery practices was taken into account. Data were not complete for all eligible women, including data on planned place of birth. Some women do not choose their place of birth until they are in labour and in some cases the midwife might have forgotten to register this information. 'Quality of treatment' and 'general rating of care' by caregiver was not available for all women. Furthermore, women in the DELIVER study were higher educated and less often of non-Dutch origin than the general Dutch population [15]. In addition, the response rate for participation was only $62 \%$. It seems, however, unlikely that among non-responders, the association between planned place of birth and quality of care would be in the opposite direction. In this study we used the CQindex. This instrument has been validated among Dutch pregnant women [8]. A reliability analysis of the 7-items measuring 'quality of treatment by the caregiver' revealed a high internal consistency as well. However, measuring satisfaction or quality of treatment by the caregiver is a methodological challenge, and therefore we have interpreted the findings in the scope of clinical relevance in addition to statistical significance as described below.

\section{Interpretation}

To our knowledge, our study is the first to report on the association between planned place of birth and satisfaction with caregiver among women who were transferred during labour. It was shown previously that women who (planned to or actually) give birth at home have higher scores on 'general satisfaction' or 'quality of care' received from the caregiver [8, 26]. Furthermore it has been reported that women who planned a home birth were less satisfied with the caregiver and with their birth experience when they were transferred from home to hospital, compared to those who had a home birth and were not transferred $[27,28]$. These studies, however, did not compare women who had transfer of care during labour and who planned birth at home versus in hospital. Another study found that transfer of care affected evaluation of the midwife similarly among women with a planned home birth compared to those with a planned hospital birth [22]. In our study primiparous women who planned a home birth and who were transferred during labour were more satisfied with the caregiver compared to primiparous women who planned a hospital birth and who were transferred. In multiparous women the results were in the same direction, although not statistically significant.

It is remarkable that our findings are not consistent with the assumption that transport and not meeting expectation would negatively influence satisfaction with 
caregivers among women who planned home birth [14]. Notably, women who plan hospital birth need to be transported during labour at some point as well. Furthermore, women who opt for a home birth have fundamental trust in their independent ability to give birth and have a trust in the birth process in general $[20,29,30]$. Possibly, this difference in motives might cause women to rate satisfaction with the caregiver differently, e.g. 'feeling in safe hands with the caregiver'. Medical pain relief resulted in fewer women rating satisfaction with the caregiver highly among primiparous women. This partly explained a higher rating of satisfaction among women who plan home birth, since they less often receive medical pain relief. Possibly women who receive pain medication have had a longer and more exhausting labour which might affect satisfaction with caregiver.

Nevertheless, planned place of birth itself may also have some effect on satisfaction with the birth experience. Satisfaction with the caregiver differed between two different planned birth environments (home or hospital in midwife-led care), even after adjustment for confounders. It may be that midwives behave differently when they provide care in hospital than in a woman's home. Another study showed an association between environment (e.g. ward design) and behaviour of care providers [31]. In our study, primi- and multiparous women more often stated that the caregiver took them seriously, or listened to them carefully (only multiparous women), or explained things in an understandable way (only primiparous women). This confirms reports that showed that environmental changes can influence the quality of interaction with the patient [31,32]. Hospital rooms that were associated with improved patient outcomes were those that offered privacy, promoted social support and were calming [33]. It seems likely that the home environment satisfies these aspects more often than a hospital environment.

The cut-off point for satisfaction differentiated between very satisfied versus less than very satisfied. The majority of women were satisfied with the caregiver most of the time. Overall, the mean difference in both ratings of 'general satisfaction' and 'quality of treatment' of women who planned a home birth compared to women who planned a hospital birth was smaller than the minimally important difference for clinical relevance [23, 24].

Apart from health outcomes, experiences of women have become increasingly important aspects of good quality care. Previous studies in the Netherlands found no association between planned home birth and severe adverse maternal and neonatal health outcomes [19, 34, 35]. Recently, we showed that feelings of control were similar among women with planned home birth and who were transferred to the hospital, compared to women with planned hospital birth who were transferred [36]. Therefore, it seems justified that women in the Netherlands are offered a choice for place of birth, either at home or hospital.

\section{Conclusion}

The current study shows that planned home birth among low risk women does not lead to reduced satisfaction with caregiver compared to planned hospital birth. In addition, a transferred planned home birth compared to a transferred planned hospital birth does not lead to a more negative experience of care received from the caregiver.

The findings in this study can help women to make a well informed choice about the place of birth. Women should be informed that when transfer of care during labour occurs, satisfaction with the caregiver is similar when planning either a home or a hospital birth. Future studies should aim to gain more insight in how care during transfer could be optimized in the Netherlands and countries with a similar maternity care system.

\section{Additional file}

Additional file 1: Third postpartum questionnaire. This questionnaire was filled in by women after birth. The questionnaire contains questions including the CQ-index (see question 54) which measures quality of treatment by caregiver, and a general rate of satisfaction with care (see question 60). (PDF $134 \mathrm{~kb}$ )

\section{Abbreviations}

CQ-index: Consumer Quality Index; LVR1: "Landelijke Verloskundige Registratie" for primary care; MID: Minimal Important Difference; PRN: Netherlands Perinatal Register; SCP: Netherlands Institute for Social Research; VIL: "Verloskundige Indicatie Lijst"

\section{Acknowledgements}

We would like to acknowledge Evelien Spelten, who helped to manage the DELIVER-study, and Monique Pereboom who helped Trudy Klomp to recruit the midwifery practices and to collect the data. Furthermore we would like to thank Myrthe Westerneng and Ruth Baron for data-management. We are grateful to all pregnant women and their midwives who gave their time and effort to take part in the study.

\section{Funding}

The research described in this article was funded by the Netherlands Organisation for Health Research and Development (ZonMw, grant number 91611016). ZonMw was not involved in study design, data collection, dataanalyses, interpretation of the results or writing the manuscript.

\section{Availability of data and materials}

The datasets analysed for the current study are available from the corresponding author on reasonable request.

\section{Authors' contributions}

CCG prepared the manuscript and analyzed the data. TK is project leader of the DELIVER study. AdJ is the initiator of this study. CCG, AdJ, TK, JVD and $\mathrm{ALJ}$ contributed to the design and critically revised earlier concepts of the paper and gave final approval of the version to be published.

\section{Ethics approval and consent to participate}

The design and conduct of the DELIVER study was approved by the Medical Ethics Committee of the VU University Medical Centre Amsterdam (2009/

284). All participants were informed about the study and they were asked to 
participate by their consulting midwife. Informed consent was obtained verbally, but each midwifery-practice had to sign a statement that informed consent would be obtained from all pregnant women. This procedure was according the Dutch law and confirmed by a Dutch legal office in the year 2006-2007 when the DELIVER study was designed. Inclusion of participants occurred on an opting-out basis. Client participation was voluntary and they could withdraw at any time. Privacy was guaranteed in accordance with Dutch legislation. Clients' anonymity was maintained by using anonymous patient and practice identifiers.

\section{Consent for publication}

Not applicable.

\section{Competing interests}

JVD is a member of the editorial board for BMC Pregnancy and Childbirth. None of the other authors have any competing interests.

\section{Publisher's Note}

Springer Nature remains neutral with regard to jurisdictional claims in published maps and institutional affiliations.

\section{Author details}

${ }^{1}$ Department of Midwifery Science, Academie Verloskunde Amsterdam Groningen (AVAG) and the EMGO Institute for Health and Care Research, VU University Medical Center Amsterdam, Van der Boechorststraat 7, 1081 BT Amsterdam, The Netherlands. ${ }^{2}$ Department of Obstetrics and Gynaecology, Radboud University Medical Center Nijmegen, Geert Grooteplein Zuid 10, 6525 GA Nijmegen, the Netherlands. ${ }^{3}$ Department of Women studies, Medical Sciences, Radboud University Medical Center Nijmegen, Geert Grooteplein Zuid 10, 6525 GA Nijmegen, the Netherlands.

\section{Received: 20 March 2017 Accepted: 5 July 2017}

\section{Published online: 14 July 2017}

\section{References}

1. Rijnders M, Baston H, Schonbeck Y, van der PK PM, Green J, et al. Perinatal factors related to negative or positive recall of birth experience in women 3 years postpartum in the Netherlands. Birth. 2008;35(2):107-16.

2. Ayers $\mathrm{S}$, Eagle $\mathrm{A}$, Waring $\mathrm{H}$. The effects of childbirth-related post-traumatic stress disorder on women and their relationships: a qualitative study. Psychol Health Med. 2006;11(4):389-98.

3. Gottvall K, Waldenstrom U. Does a traumatic birth experience have an impact on future reproduction? BJOG. 2002;109(3):254-60.

4. Righetti-Veltema M, Conne-Perreard E, Bousquet A, Manzano J. Risk factors and predictive signs of postpartum depression. J Affect Disord. 1998;49(3):167-80.

5. Simkin P. Just another day in a woman's life? Women's long-term perceptions of their first birth experience. Part I Birth. 1991;18(4):203-10.

6. Tuohy A, McVey C. Experience of pregnancy and delivery as predictors of postpartum depression. Psychol Health Med. 2008;13(1):43-7.

7. Wiklund I, Edman G, Ryding EL, Andolf E. Expectation and experiences of childbirth in primiparae with caesarean section. BJOG. 2008;115(3):324-31.

8. Wiegers $T$. The quality of maternity care services as experienced by women in the Netherlands. BMC Pregnancy Childbirth. 2009;9(1):18

9. Larkin P, Begley CM, Devane D. Women's experiences of labour and birth: an evolutionary concept analysis. Midwifery. 2009;25(2):e49-59.

10. Stichting Perinatale Registratie Nederland. Perinatale Zorg in Nederland 2008. Utrecht: Stichting Perinatale Registratie Nederland; 2011.

11. Perined. Perinatale Zorg in Nederland 2014. Utrecht: Perined; 2015.

12. Rowe R, Kurinczuk J, Locock L, Fitzpatrick R. Women's experience of transfer from midwifery unit to hospital obstetric unit during labour: a qualitative interview study. BMC Pregnancy and Childbirth. 2012;12(1):129.

13. Obstetric Vademecum. Final report of the Maternity Care Committee of the College of health insurance companies. Verloskundig Vademecum. Eindrapport van de Commissie Verloskunde van het College voor zorgverzekeringen]. De Koninklijke Nederlandse Organisatie van Verloskundigen (KNOV), De Landelijke Huisartsen Vereniging (LHV), De Nederlandse Vereniging voor Obstetrie en Gynaecologie (NVOG), Zorgverzekeraars Nederland (ZN), Inspectie voor de Gezondheidszorg, editors. Diemen; 2003.

14. Chervenak FA, McCullough LB, Brent RL, Levene Ml, Arabin B. Planned home birth: the professional responsibility response. Am J Obstet Gynecol. 2013; 208(1):31-8
15. Manniën J, Klomp T, Wiegers TA, Pereboom M, Brug J, de Jonge A et al Evaluation of primary care midwifery in the Netherlands: design and rationale of a dynamic cohort study (DELIVER). BMC Health Serv Res. 2012; $12: 69$.

16. Wiegers TA. Kwaliteit van zorg rond zwangerschap, bevalling en kraambed volgens cliënten. Meetinstrumentontwikkeling. Utrecht: NIVEL; 2007. 2014.

17. Williams B, Coyle J, Healy D. The meaning of patient satisfaction: an explanation of high reported levels. Soc Sci Med. 1998;47(9):1351-9.

18. van Teijlingen ER, Hundley V, Rennie AM, Graham W, Fitzmaurice A. Maternity satisfaction studies and their limitations: "What is, must still be best". Birth. 2003;30(2):75-82.

19. De Jonge A, Geerts CC, van der Goes BY, Mol BW, Buitendijk SE, Nijhuis JG. Perinatal mortality and morbidity up to 28 days after birth among 743070 low risk planned home births: a cohort study based on three merged national perinatal databases. BJOG. 2015;122(5):720-8.

20. van Haaren-Ten HT, Hendrix M, Nieuwenhuijze M, Bude L, de Vries R, Nijhuis J. Preferred place of birth: Characteristics and motives of low-risk nulliparous women in the Netherlands. Midwifery. 2012;28(5):609-18.

21. Waldenstrom U, Hildingsson I, Rubertsson C, Radestad I. A negative birth experience: prevalence and risk factors in a national sample. Birth. 2004; 31(1):17-27.

22. Wiegers TA, van der Zee J, Keirse MJ. Transfer from home to hospital: what is its effect on the experience of childbirth? Birth. 1998;25(1):19-24.

23. Kazis LE, Anderson JJ, Meenan RF. Effect sizes for interpreting changes in health status. Med Care. 1989;27(3 Suppl):S178-89.

24. Turner D, Schunemann HJ, Griffith LE, Beaton DE, Griffiths AM, Critch JN, et al. The minimal detectable change cannot reliably replace the minimal important difference. J Clin Epidemiol. 2010;63(1):28-36.

25. Hendrix M, Van HM, Moreta D, Nieman F, Nieuwenhuijze M, Severens J, et al. Why women do not accept randomisation for place of birth: feasibility of a RCT in The Netherlands. BJOG. 2009:116(4):537-42.

26. Janssen PA, Carty EA, Reime B. Satisfaction with planned place of birth among midwifery clients in British Columbia. J Midwifery Womens Health. 2006;51(2):91-7.

27. Lindgren HE, Radestad I, Hildingsson I. Transfer in planned home births in Sweden-effects on the experience of birth: a nationwide population-based study. Sex Repro Healthc. 2011;2(3):101-5.

28. Christiaens W, Gouwy A, Bracke P. Does a referral from home to hospital affect satisfaction with childbirth? A cross-national comparison. BMC Health Serv Res. 2007;7:109.

29. Boucher D, Bennett C, McFarlin B, Freeze R. Staying home to give birth: why women in the United States choose home birth. J Midwifery Womens Health. 2009;54(2):119-26.

30. Lindgren $\mathrm{H}$, Erlandsson $\mathrm{K}$. Women's experiences of empowerment in a planned home birth: a Swedish population-based study. Birth. 2010;37(4):309-17.

31. Tyson GA, Lambert $G$, Beattie $L$. The impact of ward design on the behaviour, occupational satisfaction and well-being of psychiatric nurses. Int J Ment Health Nurs. 2002:11(2):94-102.

32. Hodnett ED, Stremler R, Weston JA, McKeever P. Re-conceptualizing the hospital labor room: the PLACE (pregnant and laboring in an ambient clinical environment) pilot trial. Birth. 2009;36(2):159-66.

33. Ulrich R, Quan X, Zimring C, Joseph A, Choudhary R. The role of the physical environment in the hospital of the $21^{\text {st }}$ century: A once-in-alifetime opportunity. 2004. https://www.healthdesign.org/sites/default/files/ Role\%20Physical\%20Environ\%20in\%20the\%2021st\%20Century\%20Hospital_ 0.pdf.

34. de Jonge A, Mesman JA, Mannien J, Zwart JJ, van Dillen J, van Roosmalen J. Severe adverse maternal outcomes among low risk women with planned home versus hospital births in the Netherlands: nationwide cohort study. BMJ. 2013;346:f3263.

35. van der KJ, Poeran J, de Graaf JP, Birnie E, Denktass S, Steegers EA et al. Planned home compared with planned hospital births in the Netherlands: intrapartum and early neonatal death in low-risk pregnancies. Obstet Gynecol 2011; 118(5):1037-1046.

36. Geerts CC, Klomp T, Lagro-Janssen AL, Twisk JW, van Dillen J, de Jonge A. Birth setting, transfer and maternal sense of control: results from the DELIVER study. BMC Pregnancy Childbirth. 2014;14:27. 